\title{
Desenvolvimento de um jogo sério para ensino sobre a elaboração, operação e manutenção de plantas industriais
}

Development of a serious game for training on the development, operation and maintenance of industrial plants

\author{
M. M. Barbat ${ }^{1}$; N. C. Dutra ${ }^{1}$; D. F. Adamatti ${ }^{1 *}$; A. V. Werhli ${ }^{1}$ \\ ${ }^{1}$ Centro de ciências Computacionais/LAMSA/C3, Universidade Federal do Rio Grande, 96200000, Rio Grande-RS, \\ Brasil \\ *dianaada@gmail.com
}

(Recebido em 22 de setembro de 2014; aceito em 29 de dezembro de 2014)

\begin{abstract}
A necessidade de desenvolvimento de ferramentas que auxiliem o educador no processo pedagógico e incentivem o aluno a manter-se atraído pelo assunto em pauta é de grande importância. Com base neste tema, este trabalho tem o propósito de desenvolver um jogo sério do tipo simulador, capaz de ser utilizado por estudantes do ensino médio e superior, incentivando o aprendizado de tópicos de física e automação industrial, através da elaboração e experimentação de plantas industriais. Desta forma, proporcionando aos alunos um ambiente interativo para o estudo de fenômenos envolvidos em processos industriais que necessitem de demonstrações e ensaios práticos.
\end{abstract}

Palavras-chave: jogos sérios, plantas industriais, educação.

The need to develop tools that assist the educator in the learning process and encourage students to remain attracted by the subject matter is of great importance. This paper aims to develop a serious gametype simulator, able to be used by students in secondary and higher education by encouraging the learning of topics in physics and industrial automation, through development and experimentation of industrial plants. Thus, providing students with an interactive environment for the study of phenomena involved in industrial processes that require demonstrations and practical tests.

Keywords: Serious games, industrials plants, education.

\section{INTRODUÇÃO}

Os processos educacionais sofrem constantes mudanças ao longo dos anos, impulsionados por técnicas e ferramentas que surgem com o intuito de somar meios de aprimorar a absorção dos conhecimentos apresentados, e também, proporcionar formas de aprendizagem mais eficazes, dinâmicas e diversificadas.

A simulação tem por princípio facilitar a cognição, desenvolver competências e convicções em tópicos através da experimentação prática, dispensando à necessidade de recursos táteis que antes eram necessários para o estudo dos processos envolvidos em ambientes reais. Segundo [1], a simulação permite que se verifique o funcionamento de algum ambiente real em um ambiente virtual, gerando modelos que se comportem como aquele, considerando a variabilidade do sistema e demonstrando o que acontecerá na realidade de forma dinâmica.

O desenvolvimento de simuladores educacionais está inserido na área dos jogos sérios, área que apresenta real expansão e aceitabilidade no mercado atual, considerando que empresas consolidadas focam parte de sua atenção para a utilização desta tecnologia como ferramentas em diferentes ramos de atuação. São exemplos de empresas que utilizam jogos sérios e simuladores para treinamento de funcionários: McDonald's, Burger King, Coca-Cola, Intel, Petrobrás e Marinha do Brasil.

Este trabalho apresenta o desenvolvimento de um jogo sério para o ensino de plantas industriais. Para sua realização, primeiramente é apresentado um referencial teórico na área, apresentado na seção 2 . A seção 3 apresenta o jogo proposto e os resultados encontrados até o momento. Na seção 4 estão as conclusões do trabalho até o momento, bem como os trabalhos futuros propostos. 


\section{REFERENCIAL TEÓRICO}

\section{Jogos Sérios como Ferramentas Didáticas}

Diversos estudos foram feitos com o intuito de validar a utilização de jogos educacionais e simuladores no processo educacional de crianças, jovens e adultos. Na grande maioria dos casos foram obtidos resultados positivos quanto à assimilação, aceitabilidade e convicção sobre os tópicos abordados. De modo geral, a explicação mais utilizada por estudiosos desta área ressalta que com a utilização de simuladores e jogos educacionais, torna-se mais intuitiva a transferência do conhecimento, pois, através ou em conjunto com o entretenimento, a aprendizagem tende a convergir de forma que o jogador/aluno aprenda o que foi passado de forma passiva e agradável. Porém, é importante salientar que o conceito e utilização dos jogos como via para aprendizado não é um conceito atual, a utilização de jogos para educação e treinamento, surgiu com o Army Battlezone, projeto desenvolvido pela Atari na década de 80, concebido com o intuito de desenvolver novas formas de treinamentos militares em situações de batalha. Desde então, vem crescendo e sendo abordado seu uso ao longo dos anos em inúmeras áreas como: setor petrolífero, setor automotivo, setor aeroviário, treinamento gerencial, gestão de pessoas, acessibilidade de pessoas com necessidades especiais, medicina entre outras. Para compreendermos melhor como a simulação é aplicada a educação, de acordo com [5], a simulação é um meio de se experimentar ideias e conceitos sob condições que estariam além das possibilidades de se testar na prática, devido ao custo, demora ou riscos envolvidos.

Assim, percebe-se a importância dos simuladores e jogos educacionais como ferramentas inseridas no processo de aprendizado de diferentes áreas do conhecimento, principalmente nos dias atuais os quais, a tecnologia e os jogos eletrônicos estão cada vez mais presente na vida e formação dos jovens.

\section{Plantas Industriais}

A elaboração de Plantas Industriais envolve procedimentos bem estruturados que compõem uma serie de mecanismos que fazem parte da manufatura de um ou vários itens. Os processos representados e as diferentes estruturas são representados através de fluxogramas de engenharia padronizados (Figura 1), amparados por normas internacionais que proporcionam alto grau de utilização em todos os níveis de produção, pois evidenciam os componentes do sistema de forma que possam ser estipuladas maneiras adequadas de desenvolvimento, proporcionando melhor aproveitamento estratégico de recursos e possibilitando análises de viabilidade técnica, viabilidade econômica, estética, ergonomia do produto e impacto ambiental [3].

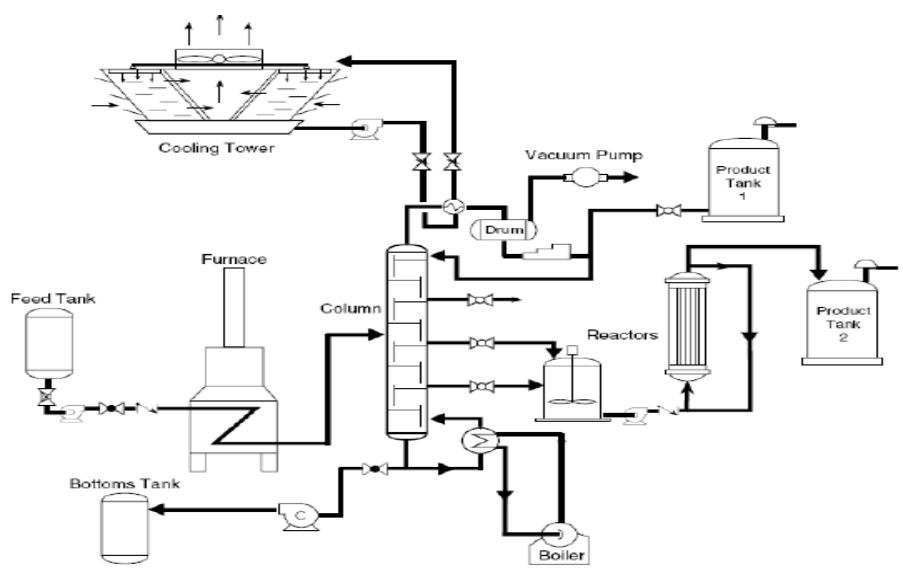

Figura 1- Exemplo de fluxograma de engenharia P\&ID [4].

A elaboração de plantas industriais envolve conjuntos de sistemas dinâmicos que podem ser modelados fisicamente, através de plantas piloto e protótipos, ou matematicamente, através da abstração da realidade por meio de equações. 


\section{O JOGO PROPOSTO}

O projeto de construção deste jogo envolve técnicas de Engenharia de Software, e Padrões de Projetos. Toda a modelagem do jogo pode ser encontrada em [6].

O jogo, desenvolvido em Java, possui três fases. Nas quais o aluno poderá manipular inicialmente os seguintes recurso: tanques cilíndricos, válvulas de controle, bombas hidráulicas e dutos hidráulicos. Como parte do processo de aprendizado, no decorrer das fases os componentes serão configurados e relacionados pelo usuário, ou seja, parâmetros como vasão, diâmetro e potência serão ajustados pelo aluno de modo a simular o processo dinâmico solicitado. É importante salientar que a cada nova fase, telas explicativas sobre o problema a ser solucionado serão apresentadas. Contudo, a qualquer momento, o aluno poderá requerer uma breve explicação ou ajuda de determinado componente do simulador ou da fase. As Figuras 2 e 3 apresentam a tela inicial do jogo e as duas primeiras fases, respectivamente.

$\mathrm{Na}$ primeira fase o usuário apenas tem que passar a água do primeiro tanque para o segundo no menor tempo possível. É interessante que aqui o usuário se harmonize com os primeiros componentes de plantas industriais que a fase propicia. Já na segunda fase o jogador precisa deixar os dois tanques menores em equilíbrio, para isso a bomba deve ser configurada de modo a passar toda a água no menor tempo possível.

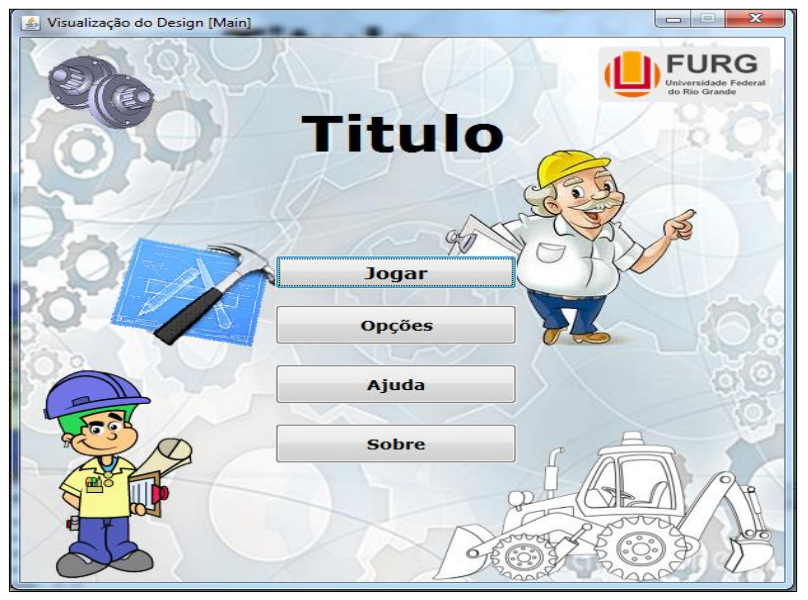

Figura 2 - Tela Inicial do jogo
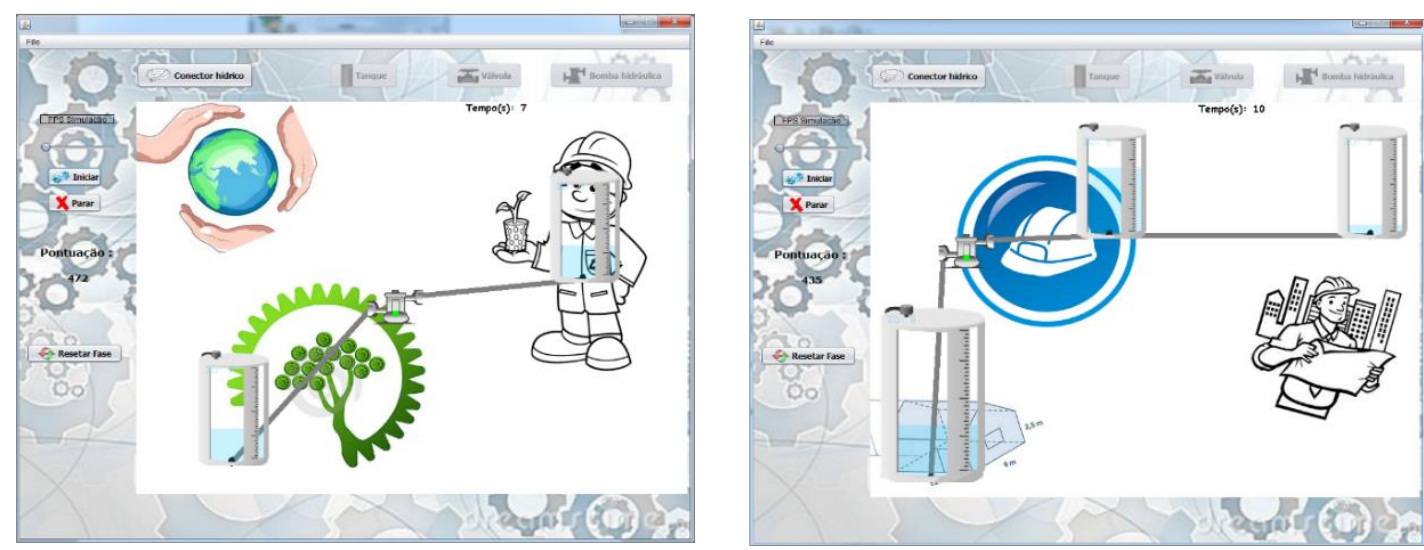

(a)

(b)

Figura 3. Fases do Jogo. Em (a) primeira fase. Em (b) segunda fase.

Ao passo que o aluno entra no jogo é requerido seu nome, a partir daí sua entrada ficará salva juntamente com a data de acesso. Quando o jogador finalizar cada fase, aparecerá uma janela mostrando a pontuação alcançada naquela etapa, calculada através do tempo, e será acrescentado a tabela Fase dados como número da fase e tempo. Já as tabelas dos componentes hidráulicos são preenchidas de acordo com a configuração dos componentes do simulador, na 
qual todos os parâmetros configuráveis, técnicas de jogo e tempo utilizados pelo jogador são salvos a fim de futuramente analisar e encontrar perfis de alunos no jogo.

O banco de dados é implementado através do PostgreSQL. A base de dados contém 6 tabelas: Usuário, que guarda dados como nome e data em que foi acessado o jogo; Fase, que tem o código, número da fase e tempo gasto para concluí-la; e as tabelas referentes aos componentes disponíveis no jogo, todos eles contendo seu código, código da fase que por consequência contém o código do jogador e os parâmetros que o usuário atribuiu ao longo das fases (Figura 4).

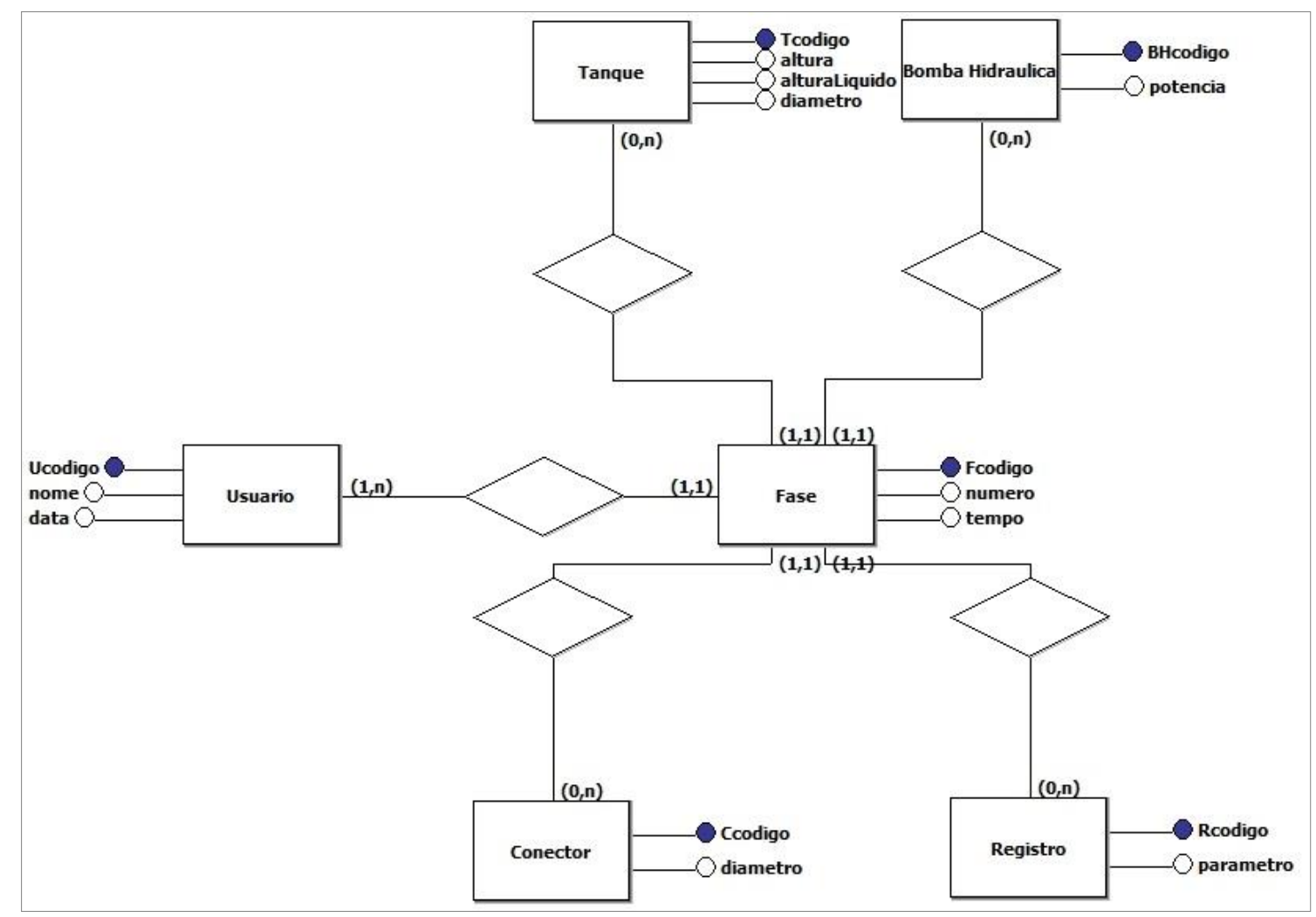

Figura 4. Modelo Entidade Relacionamento da base de dados.

\section{Resultados preliminares}

A fim de constatar cada perfil de jogador o jogo foi testado em dois grupos de alunos do ensino médio, totalizando 25 alunos. Os alunos do primeiro grupo testaram a primeira fase e deram diversas sugestões de como o jogo poderia ser melhorado. A partir dessas sugestões dos próprios jogadores, o jogo foi se alterando a fim de o tornar mais atrativo aos olhos dos alunos do ensino médio. Depois de duas semanas foi feito um segundo teste, agora com duas fases, com o outro grupo de alunos. Nesse segundo encontro, os alunos encontraram uma jogabilidade muito melhor do que antes visto que componentes como movimentação dos objetos e funções como resetar fase foram aprimorados e adicionados.

\section{CONCLUSÃO}

Este artigo apresentou a proposta de um jogo sério para o ensino sobre plantas industriais a estudantes do ensino médio e de graduação em cursos de engenharia que tenham em seu currículo esse tema. 
Acredita-se que a utilização de jogos sérios possa ser um motivacional para o ensino de disciplinas ditas "difíceis", de forma lúdica e intuitiva. A implementação do jogo é baseada em padrões de projeto, visualizando sua modularidade e reuso.

Também foi desenvolvido em Java, como forma a garantir sua portabilidade. O jogo já foi testado com dois grupos de alunos do ensino médio, para verificar usabilidade e entendimento do jogo, bem como armazenar suas jogadas, de forma a popular o banca de dados desenvolvido, para que se possa analisar os dados, identificando perfis de jogadores, a partir de técnicas de mineração de dados.

\section{REFERÊNCIAS BIBLIOGRÁFICAS}

1. Cassel RA. Desenvolvimento de uma abordagem para a divulgação da simulação no setor calçadista gaúcho. Dissertação de Mestrado apresentada ao Programa de Pós-Gradução em Engenharia de Produção (PPGEP) da Universidade Federal do Rio Grande do Sul (UFRGS), 1996.

2. Eykhoff P. System identification: parameter and state estimation. Chichester, England: Wiley, 1974. 555 p. [University of Technology, Eindhoven, The Netherlands]

3. Garcia C. Modelagem e Simulação de Processos Industriais e de Sistemas Eletromecânicos. $2^{\mathrm{a}}$ ed. Ver. E ampl., 1. Reimp. - São Paulo: Editora da Universidade de São Paulo, 2009.

4. Kuphaldt TR. Instrumentation Lessons In Industrial Instrumentation. Version 0.2 Realesed September 29, 2008.

5. Martinelli DP. A Utilização de Jogos de Empresas no Ensino da Administração, São Paulo, FEAUSP, Dissertação de Mestrado, 1987.

6. Barbat MM, Werhli AV, Adamatti DF. Engenharia de Software Aplicada no Desenvolvimento de uma Plataforma para Simulaçao de Processos Dinamicos. In: XXV Congresso Regional de Iniciação Científica e Tecnológica em Engenharia, 2013, Passo Fundo/RS. CRICTE 2013. p.: 1-4. 